\title{
Methionine controlled impediment of secondary nucleation leading to nonclassical growth within self-assembled de novo gold nanoparticles
}

Jitendra Sahu

Indian Institute of Technology Roorkee https://orcid.org/0000-0002-0720-4407

Shahbaz Lone

Indian Institute of Technology Roorkee

Kalyan Sadhu ( $\sim$ sadhu@cy.iitr.ac.in )

Indian Institute of Technology Roorkee https://orcid.org/0000-0001-5891-951X

\section{Research Article}

Keywords: gold nanoparticle, seed, methionine, secondary nucleation, self-assembly, nonclassical growth

Posted Date: November 29th, 2021

DOI: https://doi.org/10.21203/rs.3.rs-961831/v2

License: (c) (i) This work is licensed under a Creative Commons Attribution 4.0 International License.

Read Full License 


\title{
Methionine controlled impediment of secondary nucleation leading to nonclassical growth within self-assembled de novo gold nanoparticles
}

\author{
Jitendra K. Sahu, Shahbaz. A. Lone and Kalyan K. Sadhu*
}

\begin{abstract}
The conventional key steps for seed mediated growth of noble metal nanostructures involve classical and nonclassical nucleation. Furthermore, the surface of the seed catalytically enhances the secondary nucleation involving $\mathrm{Au}^{+}$to $\mathrm{Au}^{0}$ reduction, thus providing in-plane growth of seed. In contrast to this well-established growth mechanism, herein we report the unique case of methionine (Met) controlled seed mediated growth reaction, which rather proceeds via impeding secondary nucleation in presence of citrate stabilized gold nanoparticle (AuNP). The interaction between the freshly generated $\mathrm{Au}^{+}$and thioether group of Met in the medium restricts the secondary nucleation process of further seed catalyzed $\mathrm{Au}^{+}$reduction to $\mathrm{Au}^{0}$. This incomplete conversion of $\mathrm{Au}^{+}$, as confirmed by X-ray photoelectron spectroscopy (XPS), results in a significant enhancement of the zeta $(\zeta)$ potential even at low Met concentration. Nucleation of in situ generated small-sized particles (nAuNPs) takes place on the parent seed surface followed by their segregation from the seed. Self-assembly process of these nAuNPs arises from the aurophilic interaction among the $\mathrm{Au}^{+}$. Furthermore, the time dependent growth of smaller particles to larger sized particles through assembly and merging within the same self-assembly validates the nonclassical growth. This strategy has been successfully extended towards the seed mediated growth reaction of AuNP in presence of three bio-inspired decameric peptides having varying number of
\end{abstract}


Met residues. The study confirms the nucleation strategy even in presence of single Met residue in the peptide and also the self-assembly of nucleated particles with increasing Met residues within the peptide.

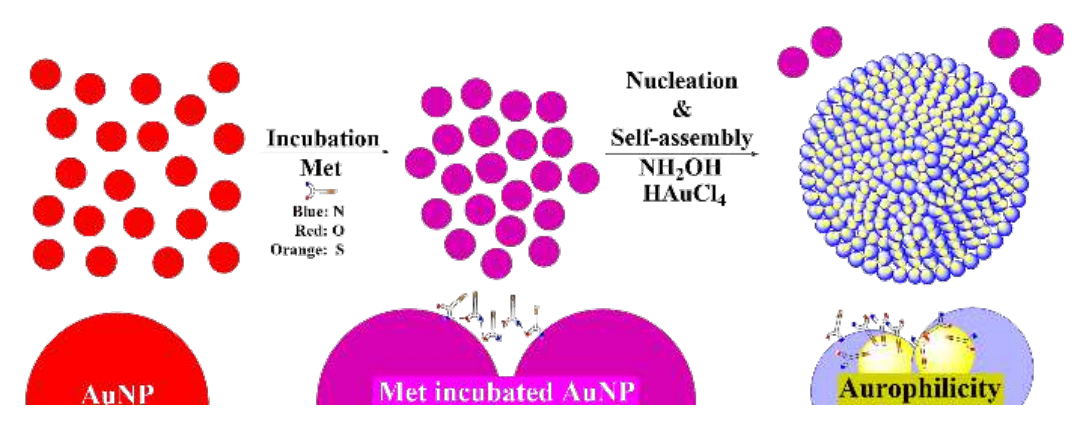

\section{KEYWORDS}

gold nanoparticle, seed, methionine, secondary nucleation, self-assembly, nonclassical growth

\section{INTRODUCTION}

Secondary nucleation is one of the crucial steps in the growth reactions involving gold nanoparticles as seed or in the case of biomolecules such as amyloid fibrils. ${ }^{1,2}$ Small molecule has the ability to suppress the secondary nucleation in the growth medium for amyloid beta peptides. ${ }^{3}$ On contrary, noble metals follow secondary nucleation in their growth process in the presence of small molecules, which are rather used as capping agents, leading to a variety of final shapes. ${ }^{4}$ Weak or strong binding efficiencies of such small molecules play an important role in the growth process in general, including the growth mechanism of anisotropic gold nanoarchitecture. ${ }^{5}$ Recent report suggest that unlike classical nucleation proceeding by addition of atom to the crystal lattice via a single high energy barrier, the growth mechanism in certain cases follows an oriented attachment among nanoparticles involving a low defect-free energy pathway for nonclassical growth. ${ }^{6}$ Intermediate synthesis at the molecular level has been traced for time dependent seed 
mediated gold nanocluster growth. ${ }^{7}$ Fluctuations of surface atoms successfully demonstrated the coalescence behavior of gold nanoparticle at $873 \mathrm{~K}$ within 1 hour time span on a silicon surface. ${ }^{8}$

The concentration and functional group present in the ligand play crucial role in the prenucleation stage during gold nanoparticle synthesis, thereby influencing their architectures. ${ }^{9}$ A wide range of shape evolution from spherical gold nanoparticle seed has been reported in presence of $\mathrm{Ag}^{+}$and halides through kinetic and surface-controlled growth. ${ }^{10,11}$ The combination of icosahedral gold seed and alkylamines shows growth into highly symmetric gold nanostars. ${ }^{12}$ Not only the small molecules, but also the biomolecules such as peptides or nucleic acids play an important role in the nucleation process giving rise to various nanoarchitectures. ${ }^{13-21}$ The growth reaction of octahedral and cubic gold nanoparticle seed in presence of amino acids and peptides containing cysteine has ended up in asymmetric evolution. ${ }^{22,23} \mathrm{~A}$ handful of recent reviews have been reported focusing on the precisely defined anisotropic gold nanoparticle formation through growth reactions. ${ }^{24-26}$ Furthermore, a wide range of capping and reducing agents used for the selective growth along different facets of anisotropic gold seeds have been found to give a broad variety of final shapes..$^{27-33}$

In this work we have demonstrated experimental evidences that show the unprecedented role of methionine (Met) to impede the secondary nucleation step involved in the seed mediated growth of Au nanoparticles. The seed catalyzed $\mathrm{Au}^{+}$to $\mathrm{Au}^{0}$ conversion in the secondary nucleation step $^{1}$ is significantly inhibited through the stabilization of $\mathrm{Au}^{+}-\mathrm{S}$ (thioether, Met) interaction. ${ }^{34}$ XPS analysis after the Met controlled growth reaction confirms the stabilization of $\mathrm{Au}^{+}$species. The transmission electron microscopic (TEM) images after the growth reaction with Met variation show stepwise formation of smaller sized nucleated gold nanoparticle (nAuNP) on parent AuNP seed surface, their detachment from seed (Scheme 1). The inhibition of secondary nucleation 


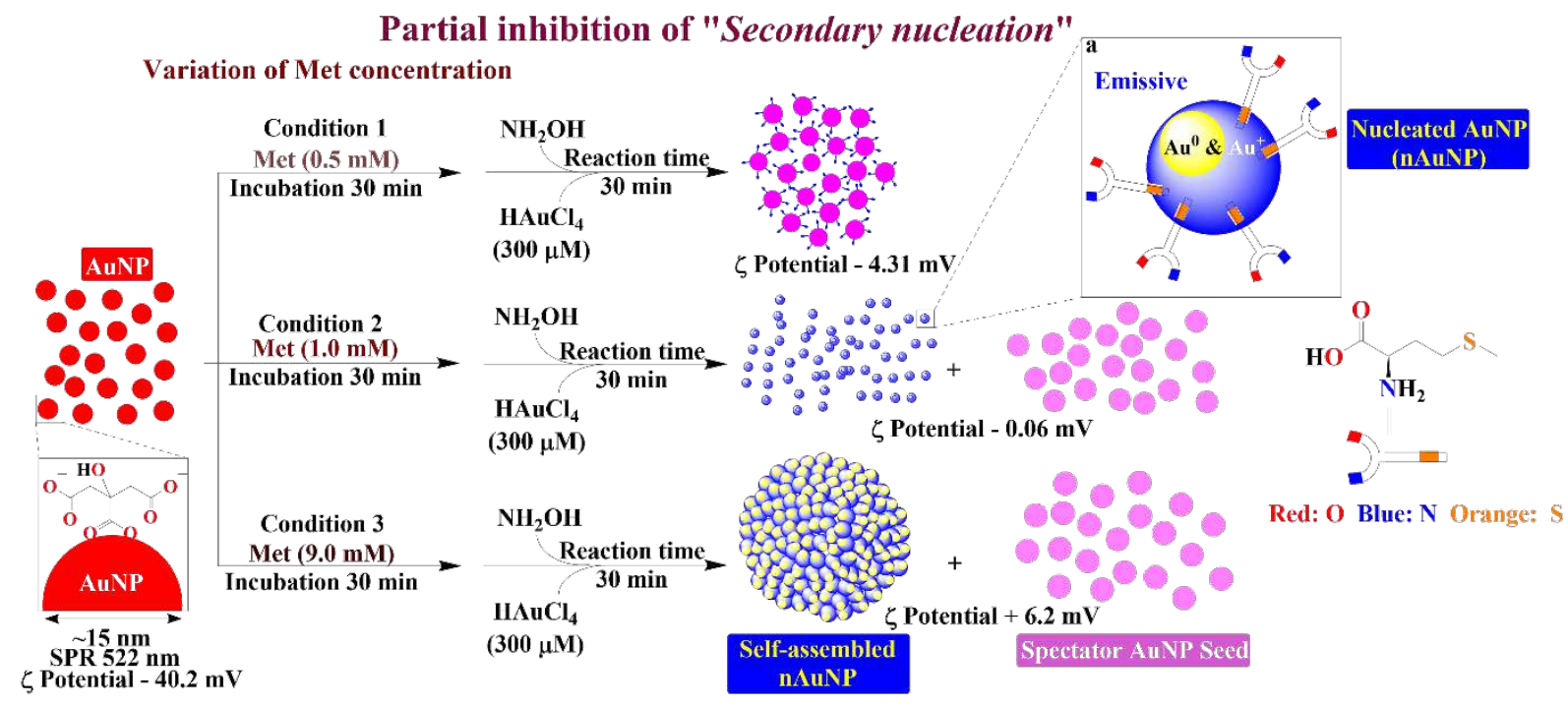

Scheme 1: Schematic illustration for the nAuNPs development from parent AuNP seed with Met variation through impediment of secondary nucleation. ${ }^{\text {a }}$ ellow spheres represents only the presence of $\mathrm{Au}^{+}$within nAuNP.

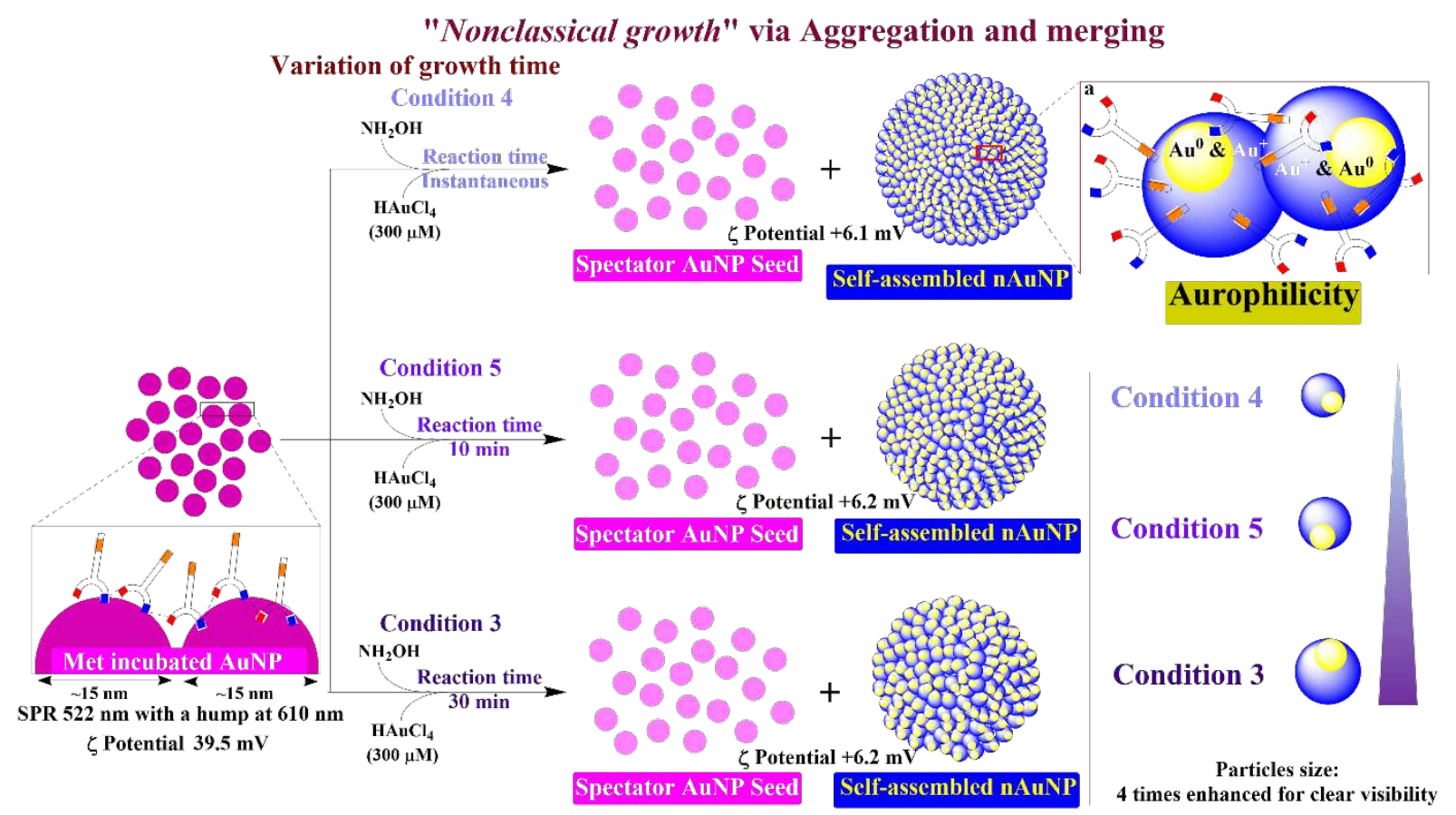

Scheme 2: Schematic illustration of the nonclassical growth within the self-assembled structures during the variation in the reaction time. ${ }^{\text {a }}$ ellow spheres represents only the presence of $\mathrm{Au}^{+}$within nAuNP. 
results in the self-assembly of these in situ generated nanoparticles (nAuNPs) through aurophilic interaction between $\mathrm{Au}^{+}{ }^{35}$ The self-assembled structures show time dependent nonclassical growth of individual small particles to larger particles by assembly and merging (Scheme 2), analogous to those observed for other noble metal nanocomposites. ${ }^{36}$ The growth reactions with a handful of sulfur containing molecules confirm the selectivity of Met for the inhibition of secondary nucleation. The unique behavior of Met in secondary nucleation and self-assembly process has been explored in the seed mediated growth reactions with three bio-inspired peptides having variable Met residues.

\section{RESULTS AND DISCUSSION}

Role of spectator seed in growth reaction. Citrate stabilized AuNP (15.0 $\pm 2.0 \mathrm{~nm}$, Figure S1), showing surface plasmon resonance (SPR) peak at $522 \mathrm{~nm}$, has been synthesized as seed for the growth reactions. The incubation of $9 \mathrm{mM}$ Met with AuNP solution (1.20 nM) changes the color of the solution to orange red and an additional small hump around $610 \mathrm{~nm}$ has been observed in the absorbance spectra (Figure S2), which is absent in case of AuNP incubation with $0.5 \mathrm{mM}$ Met. The presence of a less intense peak of Met carboxylate stretching ${ }^{37}$ frequency at $2116 \mathrm{~cm}^{-1}$ in infrared spectrum (Fig. S3) confirms weak interaction prevailing between $\mathrm{Au}^{0}$ and Met carboxylate after the $30 \mathrm{~min}$ incubation of Met to the parent AuNP seed. Addition of $300 \mu \mathrm{M} \mathrm{Au} \mathrm{u}^{3+}$ salt for the growth reaction in presence of excess hydroxylamine as reducing agent immediately turns the color of both the solutions having $0.5 \mathrm{mM}$ and $9 \mathrm{mM}$ Met concentrations into blue and SPR peaks show red shift to near $550 \mathrm{~nm}$ along with the appearance of new peaks at $688 \mathrm{~nm}$ and $696 \mathrm{~nm}$ respectively (Figure 1A). Interestingly, the TEM and high-resolution TEM (HRTEM) images from the growth reaction in presence of $0.5 \mathrm{mM}$ Met clearly suggest the generation of small nucleated 
particles of size $\sim 6 \mathrm{~nm}$ connected to the parent AuNP seed through (llll) plane (Figure 1B and 1C). This undoubtedly supports the role of the seed surface in the nucleation of the smaller AuNPs.
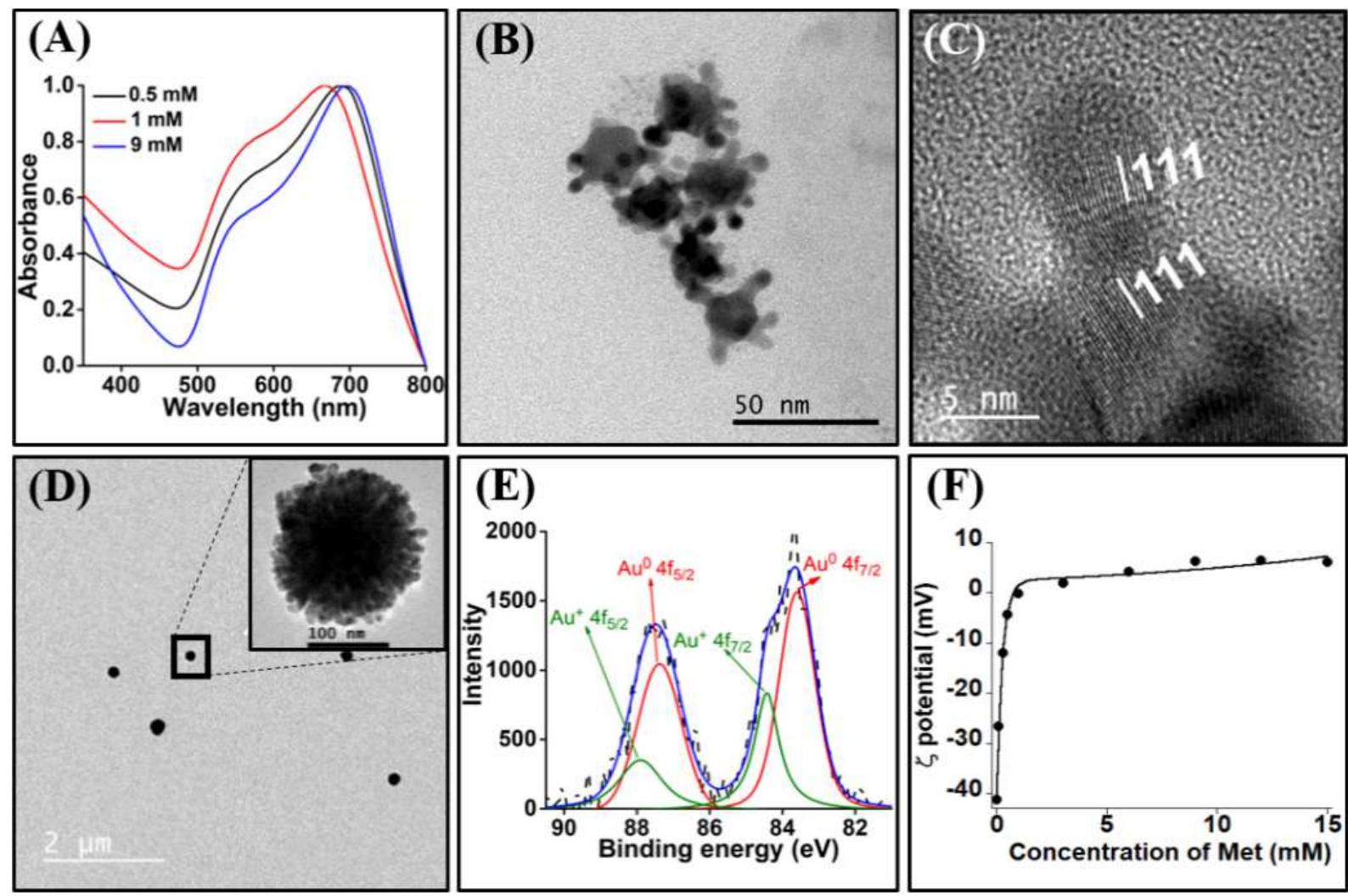

Figure 1: (A) Absorption spectra after growth reaction of AuNP seed incubated with $0.5 \mathrm{mM}, 1$ $\mathrm{mM}$ and $9 \mathrm{mM}$ Met; (B) TEM and (C) HRTEM images of nAuNPs obtained after the growth reactions from AuNP seed incubated with $0.5 \mathrm{mM}$ Met; (D) TEM image (inset: enlarged image) of the self-assembled nucleated particle obtained after the growth reactions from AuNP seed incubated with $9 \mathrm{mM}$ Met; $(\mathrm{E})$ de-convoluted XPS spectra of $\mathrm{Au} 4 \mathrm{f}_{7 / 2}$ and $4 \mathrm{f}_{5 / 2}$ showing the presence of $\mathrm{Au}^{0}$ (red) and $\mathrm{Au}^{+}$(olive); (F) Met dependent $\zeta$ potential variation after 30 min growth reaction of AuNP in presence of $300 \mu \mathrm{M} \mathrm{Au}{ }^{3+}$. Scale bar: $50 \mathrm{~nm}(\mathrm{~B}), 5 \mathrm{~nm}(\mathrm{C}), 2 \mu \mathrm{m}$ (D) and $100 \mathrm{~nm}$ (D, inset).

Time dependent absorption spectra up to $30 \mathrm{~min}$ growth reaction in presence of $9 \mathrm{mM}$ Met reveal continual redshifts of the SPR and newly generated peak (Figure S4). This growth reaction reveals spherical assemblies of average diameter $170 \mathrm{~nm}$ after $30 \mathrm{~min}$ in the TEM images (Figure 1D). Closely focusing on one such assembly, highly dense self-assembled nAuNPs has been 
observed (inset Figure 1D). Interestingly, TEM image in presence of $9 \mathrm{mM}$ Met reveals the maximum dimension $(\sim 11 \mathrm{~nm})$ of individual particle within the self-assembly; noticeably smaller than the $15 \mathrm{~nm}$ parent seed and sufficiently larger than the $6 \mathrm{~nm}$ nucleated particles developed on the parent seed surface after the growth reaction with $0.5 \mathrm{mM}$ Met. In addition to the selfassembled nAuNPs, presence of nanoparticles with $\sim 15 \mathrm{~nm}$ diameter as spectator seed (Figure S5) has been observed in the same TEM grid. It is important to note that the same growth reaction without parent seed shows no generation of SPR peak, which endorses the important role of the parent seed in the Met controlled nAuNP synthesis.

We have followed the self-assembly of nAuNPs through XPS measurements of the mixture containing spectator seeds and self-assembled nAuNPs obtained from the growth reactions in presence of $9 \mathrm{mM}$ Met (Figure S6). Deconvolution studies of binding energy for $\mathrm{Au} 4 \mathrm{f}_{7 / 2}$ and $4 \mathrm{f}_{5 / 2}$ show the presence of $\mathrm{Au}^{+}$in addition to $\mathrm{Au}^{0}$ after the growth reaction (Figure 1E). Negative control XPS study on binding energies for the parent AuNP seed show no formation of $\mathrm{Au}^{+}(\mathrm{Figure}$ S7). At the initial nucleation step, hydroxylamine as a mild reducing agent reduces the externally added $\mathrm{Au}^{3+}$ ions to $\mathrm{Au}^{+}$ions. In the standard secondary nucleation process, seed $\mathrm{AuNP}$ participates in the reduction of $\mathrm{Au}^{+}$to $\mathrm{Au}^{0}$ followed by growth of the parent seed. ${ }^{1}$ In this Met controlled growth, secondary nucleation process is partially inhibited due to the stabilization of the freshly generated $\mathrm{Au}^{+}$by the available Met in the solution. ${ }^{34}$ XPS study further confirms the presence of 3:7 ratio for $\mathrm{Au}^{+}: \mathrm{Au}^{0}$ after the growth reaction, while 4:6 ratio for $\mathrm{Au}^{3+}: \mathrm{Au}^{0}$ has been used in the growth reaction. The secondary nucleation step involving $\mathrm{Au}^{+}$conversion to $\mathrm{Au}^{0}$ has thus been restricted by $75 \%$ in presence of Met. The self-assembly process of nAuNPs has been observed due to the aurophilic interaction ${ }^{35}$ between $\mathrm{Au}^{+}-\mathrm{Au}^{+}$present in these nucleated particles. 
Variation of methionine concentration for segregation and self-assembly of nucleated particles. The difference in TEM images in presence of $0.5 \mathrm{mM}$ and $9 \mathrm{mM}$ Met concentration prompts us to follow the Met concentration stepwise $(0.1 \mathrm{mM}$ to $9 \mathrm{mM})$ in order to understand its role in the growth medium. The absorbance spectrum after the growth reaction in presence of 0.1 $\mathrm{mM}$ Met concentration displays a small hump around $700 \mathrm{~nm}$. In case of $0.3 \mathrm{mM}$ Met, a clear additional peak has been observed at $696 \mathrm{~nm}$, which further shows $30 \mathrm{~nm}$ blue shifts with increasing concentration of Met up to $1 \mathrm{mM}$ (Figure S8a). Notably after $1 \mathrm{mM}$ Met critical concentration, absorbance measurements show continuous red shift till $696 \mathrm{~nm}$ with increasing Met concentration up to $9 \mathrm{mM}$ (Figure S8b). The TEM image after 30 min of the growth reaction in presence of $1 \mathrm{mM}$ Met shows segregated nAuNP with a dimension of $\sim 6.5 \mathrm{~nm}$ (Figure S9), which is comparable to the nucleated particles of $\sim 6 \mathrm{~nm}$ size connected to the parent AuNP seed in case of $0.5 \mathrm{mM}$ Met (Figure 1B). Further increasing the Met concentration to $3 \mathrm{mM}$ produces small self-assembly of nAuNPs (Figure S10) along with the existence of the spectator seeds in the TEM images. This result is in sharp contrast to the anticipated classical growth of seed, where growth takes place on the surface of parent seed. The remaining amino acids behave differently in similar growth reaction conditions.$^{38}$ It is important to mention that the variation of $\mathrm{Au}^{3+}$ salt in the growth reaction without Met incubation shows the only enhancement in the SPR peak intensity (Figure S11).

Formation and stabilization of $\mathrm{Au}^{+}$after the growth reaction have been prominently reflected in the $\zeta$ potential change (Figure $1 \mathrm{~F}$ ). In the absence of Met, the $\zeta$ potential after the growth reaction is found to be almost similar compared to the parent AuNP, which has negative $\zeta$ potential $(-40.2 \mathrm{mV})$ due to the presence of capping citrate anions. Incubation of $0.1 \mathrm{mM}$ to $1 \mathrm{mM}$ Met with AuNP for 30 min before growth reaction shows steady enhancement of $\zeta$ potential value 
after the growth reaction and reaches almost neutral value. Interestingly, when the concentration of Met increases from $1 \mathrm{mM}$ to $15 \mathrm{mM}$, the $\zeta$ potential values slightly enhance up to $+6.5 \mathrm{mV}$. The above findings hint toward two different origins for the $\zeta$ potential and marks $1 \mathrm{mM}$ Met concentration as the critical concentration. The formation of $\mathrm{Au}^{+}$within $\mathrm{nAuNPs}$ is responsible for the significant change in the $\zeta$ potential measurements at low concentration $(0.1$ to $1 \mathrm{mM})$ of Met. The overall trend of $\zeta$ potential and Met concentration (Figure 1F) follows equation (1), where the two components are attributed to the individual interactions of $\mathrm{Au}^{+}$and $\mathrm{Au}^{0}$ with Met.

$$
\zeta=\zeta_{1} e^{-a(m)[M e t]}+\zeta_{2} e^{-b(1-m)[M e t]}
$$

In this equation, $\zeta_{1}$ and $\zeta_{2}$ are the coefficients in $\mathrm{mV}, a$ and $b$ are the constants and $m$ is the mole fraction of Met. After fitting the equation (1) for the data in Figure $1 \mathrm{~F}, \zeta_{1}, \zeta_{2}, a, b$ and $m$ values are found to be $-42.3,2.4,11.3,-0.1$ and 0.32 respectively. This expression with high positive constant $a$ (11.3) confirms the role of $\mathrm{Au}^{+}$-thioether interaction in the sharp enhancement of the $\zeta$ potential within $1 \mathrm{mM}$ Met concentration. On the other hand, the negative negligible value of constant $b(-0.1)$ due to $\mathrm{Au}^{0}$-amine interaction ${ }^{39}$ is responsible for gradual enhancement after 1 $\mathrm{mM}$ Met concentration. Considering the first part of the equation (1) exclusively, $\zeta$ potential results in saturation within $0.5 \mathrm{mM}$ to $15 \mathrm{mM}$ Met concentration range (Figure S12). XPS measurements conducted after the growth reaction in presence of $9 \mathrm{mM}$ Met clearly indicated that 0.3 mole fraction of total sulfur is present for stabilizing $\mathrm{Au}^{+}$interactions, while the remaining 0.7 mole fraction is similar to the free methionine from the deconvolution spectra of sulfur $2 \mathrm{p}_{3 / 2}$ and $2 \mathrm{p}_{1 / 2}$ (Figure S13). In coherence to the sulfur XPS, the 0.32 mole fraction (m) of total Met in equation (1) further confirms the role of Met for $\mathrm{Au}^{+}$stabilization. 
The selectivity of Met in secondary nucleation inhibition process followed by selfassembly has been investigated (Figure S14) with a few other sulfur containing molecules and inorganic salts such as 6-mercaptohexanoic acid (1), 3-mercaptopropionic acid (2), ethyl 4-amino2-(methylthio)pyrimidine-5-carboxylate (3), lipoic acid (4), oxidized and reduced glutathione $(5,6)$, sodium sulfate (7) and sodium thiosulfate (8). Classical growth of the parent AuNP seed producing the spherical gold nanoparticle of 16-18 nm diameter (Figure S15 and S16) has been observed after the growth reactions in presence of 1-8 without any positive $\zeta$ potential data. In the cases of oxidized and reduced glutathione, aggregations of the particles after growth have been observed without any self-assembled geometry.

Variation of $\mathrm{Au}^{3+}$ salt and its effect on luminescence from nAuNPs. In order to find the origin of the self-assembly after the growth reaction with $300 \mu \mathrm{M} \mathrm{Au^{3+ }}$ in presence of $9 \mathrm{mM}$ Met, the external reagent $\mathrm{Au}^{3+}$ amount has been varied during the growth reactions. The dual absorbance peaks, obtained after the growth reaction in presence of $10 \mu \mathrm{M}$ of $\mathrm{Au}^{3+}$ salt (Figure S17), have been blue shifted in comparison to the absorbance obtained for $300 \mu \mathrm{M}$ of $\mathrm{Au}^{3+}$ salt (Figure S3). With the increase of $\mathrm{Au}^{3+}$ concentration in the different growth reaction, continuous red shift trend of absorbance spectra has been observed (Figure S18). Variation of $\mathrm{Au}^{3+}$ concentration not only shows the red shift trend in the absorbance, but also results in the luminescence enhancement at $430 \mathrm{~nm}$ (Figure 2A) by exciting the solution at $412 \mathrm{~nm}$. The luminescence property has been observed during the 30 min growth reactions in presence $10 \mu \mathrm{M}$ and $300 \mu \mathrm{M} \mathrm{Au} u^{3+}$ concentration (Figure 2B). The emission intensity at $430 \mathrm{~nm}$ increases initially up to $5 \mathrm{~min}$ after the growth reaction in presence of $10 \mu \mathrm{M} \mathrm{Au} u^{3+}$ concentration, whereas the intensity does not alter in presence 
of $300 \mu \mathrm{M} \mathrm{Au}{ }^{3+}$ concentration. The excitation spectrum confirms the position of the excitation wavelength at $412 \mathrm{~nm}$ (Figure S19).
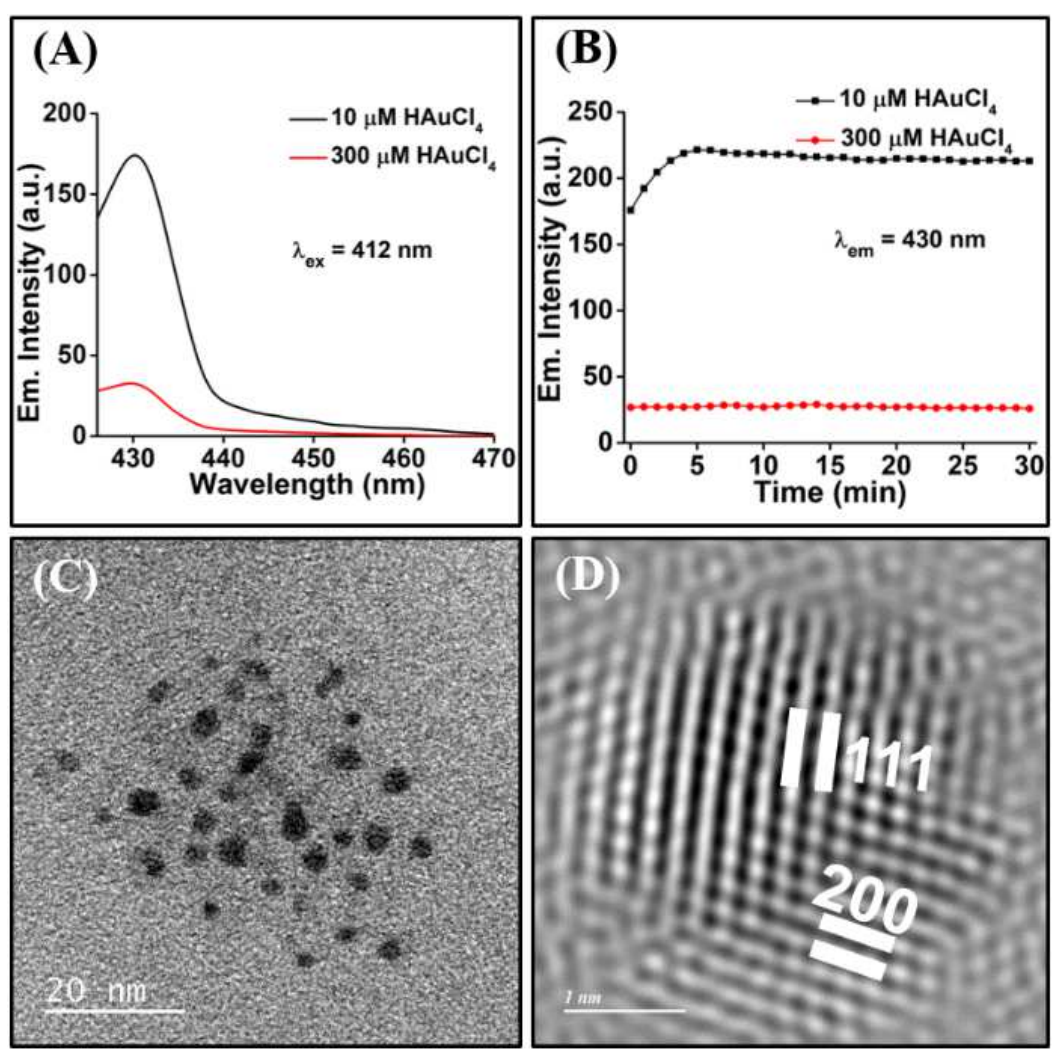

Figure 2: (A) Immediate emission spectra and (B) time dependent emission intensity after growth reaction with $300 \mu \mathrm{M}$ (red) and $10 \mu \mathrm{M} \mathrm{Au}{ }^{3+}$ (black) for AuNP seed incubated with 9 mM Met; (C) TEM and (D) HRTEM images of the nAuNP obtained after growth reaction with of $10 \mu \mathrm{M} \mathrm{Au}^{3+}$ from AuNP seed incubated with $9 \mathrm{mM}$ Met. Scale bar: 20 $\mathrm{nm}(\mathrm{C})$ and $1 \mathrm{~nm}(\mathrm{D})$.

TEM image taken after 5 min of the growth reaction with $10 \mu \mathrm{M} \mathrm{Au}{ }^{3+}$ salt shows the formation of smaller non-aggregated nAuNPs of average diameter of $\sim 2.8 \mathrm{~nm}$ (Figure $2 \mathrm{C}$ ), which is responsible for higher luminescence intensity. The HRTEM (Figure 2D) image after 5 min of growth reaction suggests the presence of both $\left(\begin{array}{lll}1 & 1 & 1\end{array}\right)$ and $\left(\begin{array}{lll}2 & 0 & 0\end{array}\right)$ planes in the instantly generated nucleated nanoparticles. With the increase in $\mathrm{Au}^{3+}$ concentration, the observed quenching in 
emission is likely to be attributed to the aggregation induced quenching within the self-assembly and/or to the larger dimension $(\sim 11 \mathrm{~nm})$ of the particle compared to the reported emissive gold nanoclusters. ${ }^{40}$ The weak emission from this $\mathrm{Au}^{+} / \mathrm{Au}^{0}$ combination in water is similar to the previous report on weakly emissive $\mathrm{Au}^{0} @ \mathrm{Au}^{+}-$thiolate-based core-shell nanocluster in $75 \%$ ethanol. ${ }^{41}$ No emissions have been observed for control experiments with the parent AuNP seed or the Met solution or the growth reaction of parent AuNP without Met incubation. Trend in $\zeta$ potential data (Figure S20) follows equation (2) during the variation of externally added $\mathrm{Au}^{3+}$ concentration for growth reaction of AuNP in presence of $9 \mathrm{mM}$ Met.

$$
\zeta=\zeta^{\prime}+c\left[\mathrm{Au}^{3+}\right]^{k}
$$

where, $\zeta^{\prime}(-39.5 \mathrm{mV})$ is the $\zeta$ potential before addition of $\mathrm{Au}^{3+}, c(4.5)$ is coefficient and $k(0.40)$ is the Met dependent conversion factor from $\mathrm{Au}^{3+}$ to $\mathrm{Au}^{+}$and $\mathrm{Au}^{0}$.

Time dependent nonclassical crystal growth within self-assembled nAuNPs. The effect of the reaction time on the nAuNP formation and their size have been monitored by varying the incubation time of Met with AuNP (Figure S21 and S22) and the growth reaction time after the addition of the $\mathrm{Au}^{3+}$ salt in the solution independently, keeping the other time parameter as constant. By performing the growth reaction for $30 \mathrm{~min}$ immediately after the addition of Met to AuNP shows aggregation of the seed followed by small-scale formation of nAuNPs (Figure S22A). Formation of smaller self-assembled nAuNPs has been observed in the case of $5 \mathrm{~min}$ incubation of Met (Figure S22B). The maximum size of the self-assembled nAuNPs has been achieved within 10 min incubation of Met with AuNP (Figure S22C). Setting the incubation time of Met with AuNP as $30 \mathrm{~min}$, the growth reaction immediately after the addition of $\mathrm{Au}^{3+}$ shows the formation of spherical self-assembly in TEM (Figure 3A). Size and $\zeta$ potential of the self- 
assembled nAuNPs remains unchanged even after $30 \mathrm{~min}$ of the growth reaction (Scheme 2).

However, the average size for each nAuNP increases from $\sim 3.5 \mathrm{~nm}$ to $\sim 11 \mathrm{~nm}$ during $30 \mathrm{~min}$ growth reaction (Figure 3A-C). HRTEM imaging captured at different time frames suggests the growth of nAuNPs through ( $\left.\begin{array}{lll}1 & 1 & 1\end{array}\right)$ crystal planes via oriented attachment leading to the
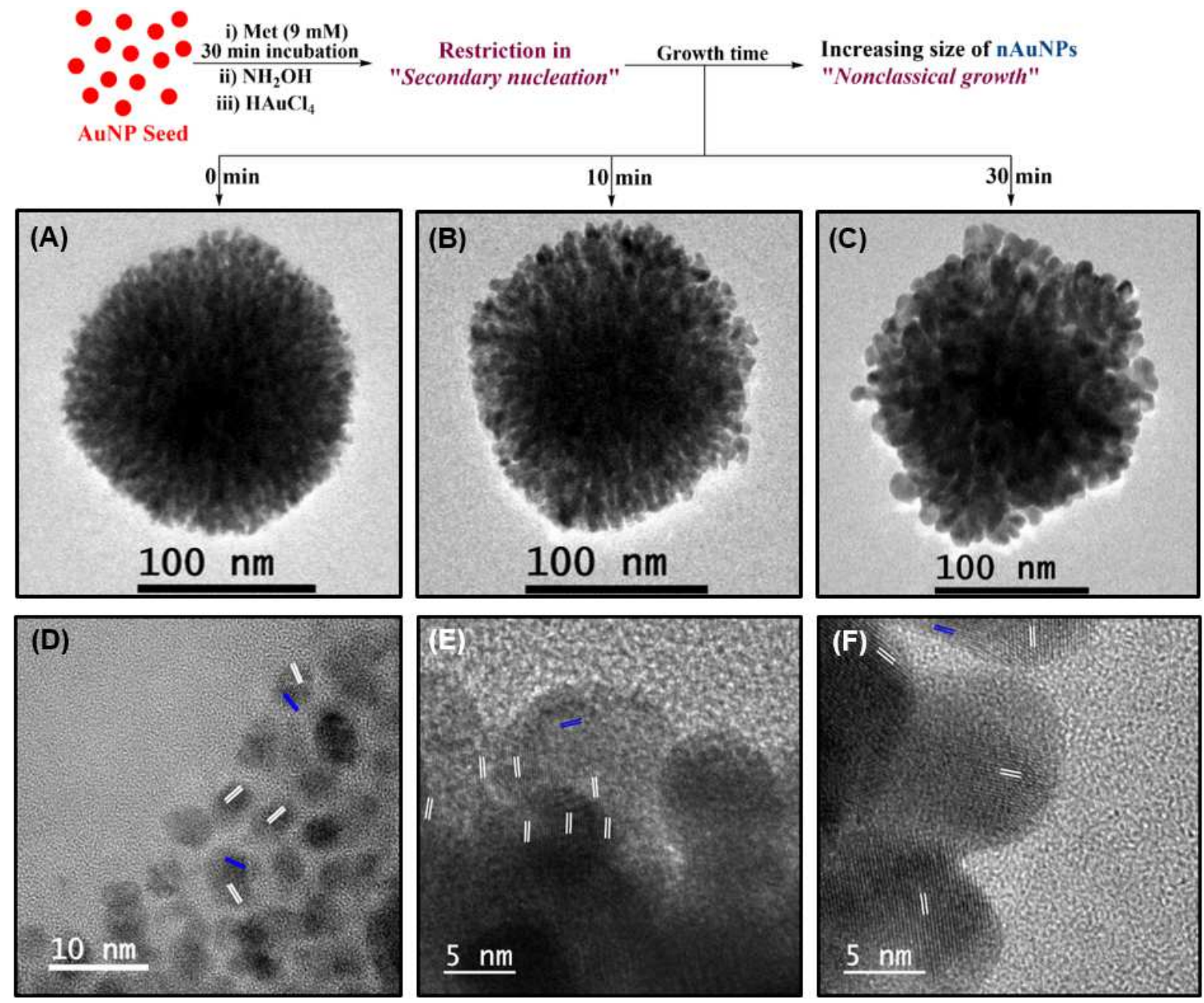

Figure 3: Met controlled nonclassical growth, (A-C) TEM and (D-F) HRTEM images of the Met incubated self-assembled nAuNPs at different time interval after the growth reaction; the average sizes of each nAuNPs are (A, D) $\sim 3.5 \mathrm{~nm}$ at $0 \mathrm{~min},(\mathrm{~B}, \mathrm{E}) \sim 7.0 \mathrm{~nm}$ at 10 $\min$ and $(\mathrm{C}, \mathrm{F}) \sim 11 \mathrm{~nm}$ at $30 \mathrm{~min}$ after the growth reaction with $300 \mu \mathrm{M} \mathrm{Au}{ }^{3+}$ from

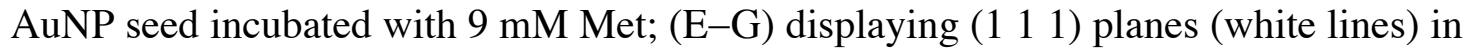
the self-assembled nAuNPs responsible for the nonclassical growth through assembly and merging along with (2 00 0) planes (blue lines). 
nonclassical crystal growth (Figure 3D-F). This change in each nucleated particle size is nonclassical ${ }^{6}$ in nature, where kinetically controlled growth by assembly and merging is responsible for the formation of larger nAuNPs.

Methionine containing peptides in secondary nucleation inhibition. The Met containing peptides have been investigated for a comprehensive understanding of the development of nAuNPs in presence of peptide amide bonds with other amino acid. Poor water solubility of hydrophobic Met unit within a peptide restricts the choice of targeted peptide size up to decameric amino acids only. Three peptide sequences $\mathrm{M}_{1}, \mathrm{M}_{3}$ and $\mathrm{M}_{5}$ [Ac-MAAAAAAAAA- $\mathrm{NH}_{2}\left(\mathrm{M}_{1}\right)$, AcMAAAMAAAAM-NH${ }_{2}\left(\mathrm{M}_{3}\right)$ and Ac-MAMAMAMAMA- $\mathrm{NH}_{2}\left(\mathrm{M}_{5}\right)$ ] have been chosen with one, three and five Met units respectively on the basis of the availability of these sequences in proteins. ${ }^{42-44}$ Growth reaction in presence of $300 \mu \mathrm{M} \mathrm{M}_{1}$ peptide shows broad absorbance spectrum (Figure 4A and S24), whereas the growth reactions after the treatment with the same concentration of $\mathrm{M}_{3}$ and $\mathrm{M}_{5}$ results in the development of additional peak around $680 \mathrm{~nm}$ and $710 \mathrm{~nm}$ respectively. The luminescence measurements at $430 \mathrm{~nm}$ after the growth reaction with these peptides confirm the decreasing trend of emission intensities from $M_{1}$ to $M_{5}$ peptides (Figure 4B). The increasing trend of $\zeta$ potential $\left(\mathrm{M}_{1}:-17.6 \mathrm{mV}, \mathrm{M}_{3}:-0.5 \mathrm{mV}\right.$ and $\mathrm{M}_{5}:+4.1 \mathrm{mV}$, Figure $\left.4 \mathrm{C}\right)$ after the growth reactions in presence of these three peptides also follows the equation (1) depending upon the total Met residues in the solutions. TEM images after the growth reactions with $\mathrm{M}_{1}$ peptide shows the formation of nAuNPs having average size $2.4 \mathrm{~nm}$ (Figure 4D). Similar studies with $\mathrm{M}_{3}$ and $\mathrm{M}_{5}$ peptides display the nAuNPs of $4.7 \mathrm{~nm}$ and $7.1 \mathrm{~nm}$ respectively (Figure 4E,F). In addition, small self-assembly of nAuNPs has been observed only after the growth in presence of $M_{5}$ peptide. Formation of self-assemblies through nAuNPs are restricted in $M_{1}$ and $M_{3}$ peptides due to additional Ala residues in these peptides. Alanine in these peptide sequences show 
non-invasive behavior during the growth reaction of AuNPs. Weak emission has been attributed to the enhanced size of nAuNPs in the case of $\mathrm{M}_{3}$ and/or the formation of self-assembly of $\mathrm{nAuNPs}$ in presence of $\mathrm{M}_{5}$.

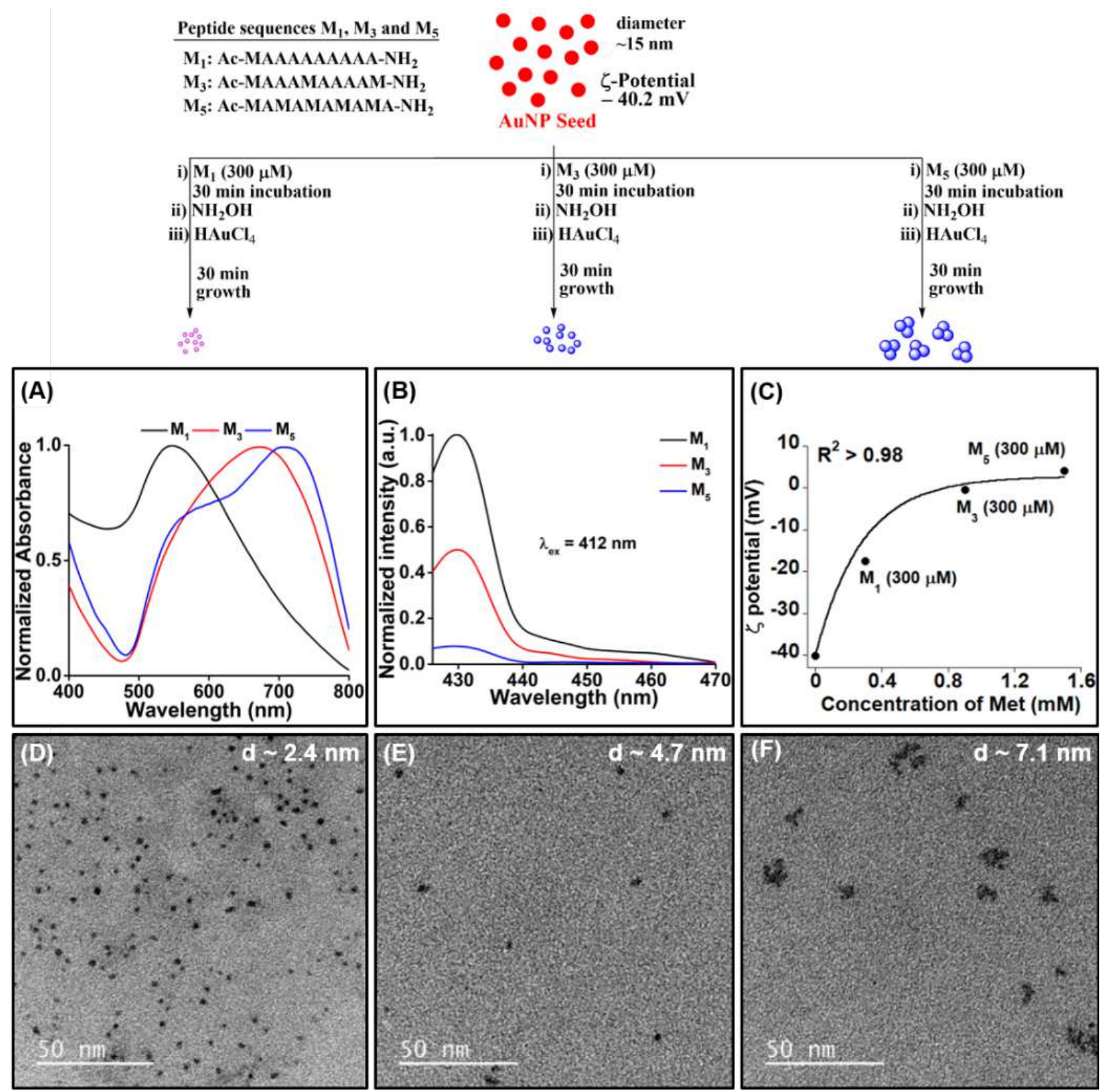

Figure 4: Formation of nAuNPs after the growth reactions of AuNP seed incubated with Met containing peptides $\mathrm{M}_{1}, \mathrm{M}_{3}, \mathrm{M}_{5}$; (A) absorbance spectra, (B) emission spectra, (C) fitting of $\zeta$ potential values with the proposed equation (1) and (D-F) TEM images (scale bar $50 \mathrm{~nm}$ ) of nAuNPs after 30 min growth reaction with $300 \mu \mathrm{M} \mathrm{Au}^{3+}$ from AuNP seed in presence of $300 \mu \mathrm{M} \mathrm{M}, \mathrm{M}_{3}, \mathrm{M}_{5}$ respectively. 


\section{CONCLUSION}

In this work, the selective formation of self-assembled nAuNPs has been demonstrated by restricting the secondary nucleation through $\mathrm{Met}$ stabilized $\mathrm{Au}^{+}$, on contrary to the conventional growth reaction of AuNP seed. The restriction in the self-assembly of nAuNPs has been achieved either by introducing less amount of Met or $\mathrm{Au}^{3+}$ salt in the growth reaction and reducing the reaction time. The segregated nAuNPs are emissive in nature, which has quenched with time due to self-assembly followed by nonclassical growth. In presence of neutral Met, this weakly emissive self-assembled nanoarchitecture shows positive $\zeta$ potential after the growth reaction, whereas the parent AuNP seed has negative $\zeta$ potential. Dramatic change in $\zeta$ potential has been correlated with Met concentration, where a certain fraction of Met participates in $\mathrm{Au}^{+}$stabilization through its thioether functional group. The time dependent nonclassical growth through aggregation and merging of nAuNPs within the self-assembly has been clearly observed through TEM imaging. This inhibition of secondary nucleation process and nonclassical growth have been successfully explored with bio-inspired decameric peptides having Met and Ala sequences. These findings open the possibility of exploring thioether functional group in the growth reaction of gold nanoparticle, for example in developing anisotropic shape within nucleated particles of smaller dimension compared to the parent seed. We are currently investigating along this direction in our laboratory.

\section{METHODS}

\section{Synthesis of AuNP seed stock solution}

$20 \mathrm{mg}(0.05 \mathrm{mmol})$ of $\mathrm{HAuCl}_{4}$ was dissolved in $90 \mathrm{~mL}$ of deionized water and refluxed at $90{ }^{\circ} \mathrm{C}$. $10 \mathrm{~mL}$ of $1 \%(\mathrm{w} / \mathrm{v})$ trisodium citrate dihydrate $(88 \mathrm{mg}, 0.3 \mathrm{mmol})$ was added to the above solution. After few minutes the color of the solution was changed to dark violet and then immediately changed to wine red. The reaction was continued for another 30 minutes in the refluxing condition and finally stopped. The AuNP solution was cooled to room temperature and the solution was characterized with the help of absorption spectroscopy and TEM image. The stock solution was 
stored at $4{ }^{\circ} \mathrm{C}$ till further use. For further experiments the seed solution was diluted and the final concentration of the solution was measured as per our previous report. ${ }^{38}$

\section{Growth reaction of AuNP with Met and high concentration of gold salt}

$300 \mu \mathrm{L}$ gold nanoparticles seed stock solution was incubated for 30 min with $30 \mu \mathrm{L}$ of $100 \mathrm{mM}$ Met. During the incubation period the color of the solution gradually changed towards reddish violet. Thereafter, $3 \mu \mathrm{L}$ of $200 \mathrm{mM} \mathrm{NH}_{2} \mathrm{OH}$ (pH 5 maintained with addition of $\mathrm{NaOH}$ ) was added to the above solutions and stirred vigorously for $10 \mathrm{~min}$ followed by the addition of $5 \mu \mathrm{L}$ of $0.8 \%$ $(\mathrm{w} / \mathrm{v}) \mathrm{HAuCl}_{4}$ to induce the reduction reaction. In each case, the final volume of the reaction was adjusted to $340 \mu \mathrm{L}$. After addition of gold salt, the reddish violet color immediately changed to blue. The solution was analyzed up to $30 \mathrm{~min}$ by different characterization techniques.

\section{Growth reaction of AuNP with Met with variable concentration of gold salt}

Different sets of $900 \mu \mathrm{L}$ gold nanoparticles seed solution were incubated separately for $30 \mathrm{~min}$ with $90 \mu \mathrm{L}$ of $100 \mathrm{mM}$ Met. During the incubation period the color of the solutions gradually changed towards reddish violet. Thereafter, $9 \mu \mathrm{L}$ of $200 \mathrm{mM} \mathrm{NH}_{2} \mathrm{OH}$ (pH 5 maintained with addition of $\mathrm{NaOH}$ ) was added to the above solutions and stirred vigorously for 10 min followed by the addition of variable amount $(0.5-50 \mu \mathrm{L})$ of $0.8 \%(\mathrm{w} / \mathrm{v}) \mathrm{HAuCl}_{4}$ to induce the reduction reaction. In these cases, the final volume of the reactions was adjusted to $1020 \mu \mathrm{L}$ by addition of deionized water. After addition of gold salt, the reddish violet color immediately changed to blue. The solution was analyzed up to 30 min by different characterization techniques.

\section{Growth reactions of AuNP with variable concentration of Met}

Different sets of $900 \mu \mathrm{L}$ gold nanoparticles seed solution were incubated separately for $30 \mathrm{~min}$ with $1 \mu \mathrm{L}, 3 \mu \mathrm{L}, 5 \mu \mathrm{L}, 10 \mu \mathrm{L}, 30 \mu \mathrm{L}, 60 \mu \mathrm{L}$ and $90 \mu \mathrm{L}$ of $100 \mathrm{mM}$ Met and $60 \mu \mathrm{L}$ and $75 \mu \mathrm{L}$ of $200 \mathrm{mM}$ Met, where the final Met concentration were maintained to $0.1 \mathrm{mM}, 0.3 \mathrm{mM}, 0.5 \mathrm{mM}, 1$ $\mathrm{mM}, 3 \mathrm{mM}, 6 \mathrm{mM}, 9 \mathrm{mM}, 12 \mathrm{mM}$ and $15 \mathrm{mM}$ respectively. During the incubation period the color of the solution gradually changed towards reddish violet at high concentration ( $3 \mathrm{mM}$ to $15 \mathrm{mM}$ ), whereas the at low concentration $(0.1 \mathrm{mM}$ to $1 \mathrm{mM})$ there was no change in color. Thereafter, 9 $\mu \mathrm{L}$ of $200 \mathrm{mM} \mathrm{NH}_{2} \mathrm{OH}$ (pH 5 maintained with addition of $\mathrm{NaOH}$ ) was added to the above solutions and stirred vigorously for $10 \mathrm{~min}$ followed by the addition of $15 \mu \mathrm{L}$ of $0.8 \%(\mathrm{w} / \mathrm{v}) \mathrm{HAuCl}_{4}$ to induce the reduction reaction. In these cases, the final volume of each reaction was adjusted to $1020 \mu \mathrm{L}$ by addition of deionized water. After addition of gold salt, the reddish violet or red color immediately changes to blue. The solutions were analyzed up to $30 \mathrm{~min}$ by different characterization techniques.

\section{Growth reactions of AuNP with variable incubation time of Met}

Different sets of $300 \mu \mathrm{L}$ gold nanoparticles seed solution were incubated for $0 \mathrm{~min}, 5 \mathrm{~min}$ and 10 min separately with $30 \mu \mathrm{L}$ of $100 \mathrm{mM}$ Met. During the incubation period the color of the solution remained unchanged up to $10 \mathrm{~min}$. There was gradually change in color towards reddish violet after $10 \mathrm{~min}$. Thereafter, $3 \mu \mathrm{L}$ of $200 \mathrm{mM} \mathrm{NH}_{2} \mathrm{OH}$ (pH 5 maintained with addition of $\mathrm{NaOH}$ ) was added to the above solutions and stirred vigorously for $10 \mathrm{~min}$ followed by the addition of $5 \mu \mathrm{L}$ of $0.8 \%(\mathrm{w} / \mathrm{v}) \mathrm{HAuCl}_{4}$ to induce the reduction reaction. In each case, the final volume of the reaction was adjusted to $340 \mu \mathrm{L}$. After addition of gold salt, the red color immediately changed to blue. The solutions were analyzed up to $30 \mathrm{~min}$ by different characterization techniques.

\section{Growth reactions of AuNP with Met containing peptides $\left(M_{1}, M_{3}\right.$ and $\left.M_{5}\right)$}


$5 \mathrm{mM}$ stock solutions of $\mathrm{M}_{1}, \mathrm{M}_{3}$ and $\mathrm{M}_{5}$ were prepared separately in DMSO due to hydrophobic nature of Met. Three sets of $300 \mu \mathrm{L}$ gold nanoparticles seed solution were incubated for $30 \mathrm{~min}$ with $20 \mu \mathrm{L}$ of $5 \mathrm{mM} \mathrm{M}, \mathrm{M}_{3}$ and $\mathrm{M}_{5}$ peptides. During the incubation period the color of the solutions gradually changed towards reddish violet for $\mathrm{M}_{3}$ and $\mathrm{M}_{5}$ peptides with high Met content. Thereafter, $3 \mu \mathrm{L}$ of $200 \mathrm{mM} \mathrm{NH}_{2} \mathrm{OH}$ (pH 5 maintained with addition of $\mathrm{NaOH}$ ) was added to the above solutions and stirred vigorously for $10 \mathrm{~min}$ followed by the addition of $5 \mu \mathrm{L}$ of $0.8 \%(\mathrm{w} / \mathrm{v}$ ) $\mathrm{HAuCl}_{4}$ to induce the reduction reaction. In each case, the final volume of the reaction was adjusted to $340 \mu \mathrm{L}$. After addition of gold salt, the reddish violet color immediately changes to blue. The solutions were analyzed up to $30 \mathrm{~min}$ by different characterization techniques.

\title{
Growth reactions of AuNP with sulfur containing small molecules and salts (1-8)
}

Stock solutions of $100 \mathrm{mM}$ 6-mercaptohexanoic acid (1), 3-mercaptopropionic acid (2), ethyl 4amino-2-(methylthio)pyrimidine-5-carboxylate (3, thioether nucleic base), lipoic acid (4), oxidized and reduced glutathione $(5,6)$, sodium sulfate (7) and sodium thiosulfate (8) were prepared either in deionized water or $50 \%$ ethanol in deionized water. Different sets of $300 \mu \mathrm{L}$ gold nanoparticles seed solution were incubated separately for $30 \mathrm{~min}$ with $30 \mu \mathrm{L} 100 \mathrm{mM}$ of $1-$ 8 , where the final concentration was maintained to $9 \mathrm{mM}$. Thereafter, $3 \mu \mathrm{L}$ of $200 \mathrm{mM} \mathrm{NH}_{2} \mathrm{OH}$ ( $\mathrm{pH} 5$ maintained with addition of $\mathrm{NaOH}$ ) was added to the above solutions and stirred vigorously for $10 \mathrm{~min}$ followed by the addition of $5 \mu \mathrm{L}$ of $0.8 \%$ (w/v) $\mathrm{HAuCl}_{4}$ to induce the reduction reaction. In each case, the final volume of the reaction was adjusted to $340 \mu \mathrm{L}$. After addition of gold salt, the color of all of each solution immediately changed to blue except the solution containing 4,7 and 8 . The solutions were analyzed up to $30 \mathrm{~min}$ by different characterization techniques. In case of 4 , the SPR peak intensity was enhanced significantly with broadening. In case of 7, the SPR peak intensity was enhanced slightly. However, in case of 8 , there was no color change.

\section{AUTHOR INFORMATION}

\section{Corresponding Author}

Kalyan K. Sadhu - Department of Chemistry, Indian Institute of Technology Roorkee, Roorkee - 247667, Uttarakhand, India.

Email: $\underline{\text { sadhu@cy.iitr.ac.in }}$

\author{
Authors \\ Jitendra K. Sahu - Department of Chemistry, Indian Institute of Technology Roorkee, \\ Roorkee - 247667, Uttarakhand, India. \\ Shahbaz A. Lone - Department of Chemistry, Indian Institute of Technology Roorkee, \\ Roorkee - 247667, Uttarakhand, India.
}

\section{ORCID}

Jitendra K. Sahu 0000-0002-0720-4407

Kalyan K. Sadhu 0000-0001-5891-951X

\section{Author Contributions}

K.K.S. conceived the idea. S.A.L. performed the experiments with self-assembled nAuNPs having positive $\zeta$ potential. J.K.S. performed all the detail mechanistic studies. J.K.S and K.K.S. carried 
out the data analysis and wrote the manuscript. All authors discussed the results and commented on the manuscript.

\section{Notes}

The authors declare no competing financial interest.

\section{ACKNOWLEDGEMENTS}

K.K.S. acknowledges the DST Nanomission (DST/NM/NB/2018/237) and SERB-DST Grant (CRG/2018/000269) for funding.

\section{ASSOCIATED CONTENT}

\section{Supporting Information}

The supporting information contains instrumental information and Figures S1-S24.

\section{REFERENCES:}

1. Scarabelli, L.; Sánchez-Iglesias, A.; Pérez-Juste, J.; Liz-Marzán, L. M. A “Tips and Tricks” Practical Guide to the Synthesis of Gold Nanorods. J. Phys. Chem. Lett. 2015, 6, 4270-4279.

2. Thacker, D.; Sanagavarapu, K.; Frohm, B.; Meisl, G.; Knowles, T. P. J.; Linse, S. The Role of Fibril Structure and Surface Hydrophobicity in Secondary Nucleation of Amyloid Fibrils. Proc. Natl. Acad. Sci. U.S.A. 2020, 117, 25272-25283.

3. Habchi, J.; Chia, S.; Limbocker, R.; Mannini, B.; Ahn, M.; Perni, M.; Hansson, O.; Arosio, P.; Kumita, J. R.; Challa, P. K.; Cohen, S. I. A.; Linse, S.; Dobson, C. M.; Knowles, T. P. J.; Vendruscoloa, M. Systematic Development of Small Molecules to Inhibit Specific Microscopic Steps of A $\beta 42$ Aggregation in Alzheimer's Disease.Proc. Natl.Acad.Sci. U.S.A. 2017, 114, E200-E208.

4. Li, Y.; Lin, H.; Zhou, W.; Sun, L.; Samanta, D.; Mirkin, C. A. Corner-, Edge-, and FacetControlled Growth of Nanocrystals. Sci. Adv. 2021, 7, eabf1410.

5. Janicek, B. E.; Hinman, J. G.; Hinman, J. J.; Bae, S. H.; Wu, M.; Turner, J.; Chang, H.-H.; Park, E.; Lawless, R.; Suslick, K. S.; Murphy, C. J.; Huang, P. Y. Quantitative Imaging of Organic Ligand Density on Anisotropic Inorganic Nanocrystals. Nano Lett. 2019, 19, 63086314. 
6. Lee, J.; Yang, J.; Kwon, S. G.; Hyeon, T. Nonclassical Nucleation and Growth of Inorganic Nanoparticles. Nat. Rev. Mater. 2016, 1, 16034.

7. Yao, Q.; Yuan, X.; Fung, V.; Yu, Y.; Leong, D. T.; Jiang, D.-e.; Xie, J. Understanding SeedMediated Growth of Gold Nanoclusters at Molecular Level. Nat. Commun. 2017, 8, 927.

8. Wang, J.; Chen, S.; Cui, K.; Li, D.; Chen, D. Approach and Coalescence of Gold Nanoparticles Driven by Surface Thermodynamic Fluctuations and Atomic Interaction Forces. ACS Nano 2016, 10, 2893-2902.

9. Ramamoorthy, R. K.; Yildirim, E.; Barba, E.; Roblin, P.; Vargas, J. A.; Lacroix, L.-M.; Rodriguez-Ruiz, I.; Decorse, P.; Petkov, V.; Teychené, S.; Viau, G. The Role of Prenucleation in the Crystallization of Gold Nanoparticles. Nanoscale 2020, 12, 16173-16188.

10. Langille, M. R.; Personick, M. L.; Zhang, J.; Mirkin, C. A. Defining Rules for the Shape Evolution of Gold Nanoparticles. J. Am. Chem. Soc. 2012, 134, 14542-14554.

11. Lohse, S. E.; Burrows, N. D.; Scarabelli, L.; Liz-Marzán, L. M.; Murphy, C. J. Anisotropic Noble Metal Nanocrystal Growth: The Role of Halides. Chem. Mater. 2014, 26, 34-43.

12. Niu, W.; Chua, Y. A. A.; Zhang, W.; Huang, H; Lu, X. Highly Symmetric Gold Nanostars: Crystallographic Control and Surface-Enhanced Raman Scattering Property. J. Am. Chem. Soc. 2015, 137, 10460-10463.

13. Chiu, C.-Y.; Ruana, L.; Huang, Y. Biomolecular Specificity-Controlled Nanomaterial Synthesis. Chem. Soc. Rev. 2013, 42, 2512-2527.

14. Mokashi-Punekar, S.; Walsh, T. R.; Rosi, N. L. Tuning the Structure and Chiroptical Properties of Gold Nanoparticle Single Helices via Peptide Sequence Variation. J. Am. Chem. Soc. 2019, 141, 15710-15716.

15. Tanwar, S.; Haldar, K. K.; Sen, T. DNA Origami Directed Au Nanostar Dimers for SingleMolecule Surface-Enhanced Raman Scattering. J. Am. Chem. Soc. 2017, 139, 17639-17648.

16. Bousmail, D.; Chidchob, P.; Sleiman, H. F. Cyanine-Mediated DNA Nanofiber Growth with Controlled Dimensionality. J. Am. Chem. Soc. 2018, 140, 9518-9530.

17. Shen, B.; Linko, V.; Tapio, K.; Pikker, S.; Lemma, T.; Gopinath, A.; Gothelf, K. V.; Kostiainen, M. A.; Toppari, J. J. Plasmonic Nanostructures through DNA-Assisted Lithography Sci. Adv. 2018, 4, eaap8978. 
18. Yan, F.; Liu, L.; Walsh, T. R.; Gong, Y.; El-Khoury, P. Z.; Zhang, Y.; Zhu, Z.; Yoreo, J. J. D.; Engelhard, M. H.; Zhang, X.; Chen, C.-L.; Controlled Synthesis of Highly-Branched Plasmonic Gold Nanoparticles through Peptoid Engineering. Nat. Commun. 2018, 9, 2327.

19. Laramy, C. R.; Lopez-Rios, H.; O’Brien, M. N; Girard, M.; Stawicki, R. J.; Lee, B.; Cruz, M. O.; Mirkin, C. A. Controlled Symmetry Breaking in Colloidal Crystal Engineering with DNA. ACS Nano 2019, 13, 1412-1420.

20. Ma, X.; Huh, J.; Park, W.; Lee, L. P.; Kwon, Y. J.; Sim, S. J. Gold Nanocrystals with DNADirected Morphologies. Nat. Commun. 2016, 7, 12873.

21. Satyavolu, N. S. R.; Tan, L. H.; Lu, Y. DNA-Mediated Morphological Control of Pd-Au Bimetallic Nanoparticles. J. Am. Chem. Soc. 2016, 138, 16542-16548.

22. Lee, H.-E; Ahn, H.-Y.; Mun, J.; Lee, Y. Y.; Kim, M.; Cho, N. H.; Chang, K.; Kim, W. S.; Rho, J.; Nam, K. T. Amino Acid- and Peptide-Directed Synthesis of Chiral Plasmonic Gold Nanoparticles. Nature 2018, 556, 360-365.

23. Cho, N. H.; Byun, G. H.; Lim, Y.-C.; Im, S. W.; Kim, H.; Lee, H.-E.; Ahn, H.-Y.; Nam, K. T. Uniform Chiral Gap Synthesis for High Dissymmetry Factor in Single Plasmonic Gold Nanoparticle. ACS Nano 2020, 14, 3595-3602.

24. Zeng, C.; Zhou, M.; Chen, Y.; Jin, R. Atomically Precise Colloidal Metal Nanoclusters and Nanoparticles: Fundamentals and Opportunities. Chem. Rev. 2016, 116, 10346-10413.

25. Kang, H.; Buchman, J. T.; Rodriguez, R. S.; Ring, H. L.; He, J.; Bantz, K. C.; Haynes, C. L. Stabilization of Silver and Gold Nanoparticles: Preservation and Improvement of Plasmonic Functionalities. Chem. Rev. 2019, 119, 664-699.

26. Pearce, A. K.; Wilks, T. R.; Arno, M. C.; O'Reilly, R. K. Synthesis and Applications of Anisotropic Nanoparticles with Precisely Defined Dimensions. Nat.Rev. Chem. 2021, 5, 2145.

27. González-Rubio, G.; Mosquera, J.; Kumar, V.; Pedrazo-Tardajos, A.; Llombart, P.; Solís, D. M.; Lobato, I.; Noya, E. G.; Guerrero-Martínez, A.; Taboada, J. M.; Obelleiro, F.; MacDowell, L. G.; Bals, S.; Liz-Marzán, L. M. Micelle-Directed Chiral Seeded Growth on Anisotropic Gold Nanocrystals. Science 2020, 368, 1472-1477.

28. Wang, Y.; Counihan, M. J.; Lin, J. W.; Rodríguez-López, J.; Yang, H.; Lu, Y. Quantitative Analysis of DNA-Mediated Formation of Metal Nanocrystals. J. Am. Chem. Soc. 2020, 142, 20368-20379. 
29. Walsh, M. J.; Tong, W.; Katz-Boon, H.; Mulvaney, P.; Etheridge, J.; Funston, A. M. A Mechanism for Symmetry Breaking and Shape Control in Single-Crystal Gold Nanorods. Acc. Chem. Res. 2017, 50, 2925-2935.

30. Wang, Q.; Wang, Z.; Li, Z.; Xiao, J.; Shan, H.; Fang, Z.; Qi, L.; Controlled Growth and ShapeDirected Self-Assembly of Gold Nanoarrows. Sci. Adv. 2017, 3, e1701183.

31. Zhai, Y.; DuChene, J. S.; Wang, Y.-C.; Qiu, J.; Johnston-Peck, A. C.; You, B.; Guo, W.; DiCiaccio, B.; Qian, K.; Zhao, E. W.; Ooi, F.; Hu, D.; Su, D.; Stach, E. A.; Zhu, Z.; Wei1, W. D. Polyvinylpyrrolidone-Induced Anisotropic Growth of Gold Nanoprisms in PlasmonDriven Synthesis. Nat. Mater. 2016, 15, 889-895.

32. Lee, J.-H.; Gibson, K. J.; Chen, G.; Weizmann, Y. Bipyramid-Templated Synthesis of Monodisperse Anisotropic Gold Nanocrystals. Nat. Commun. 2015, 6, 7571.

33. Lee, H.-E.; Yang, K. D.; Yoon, S. M.; Ahn, H.-Y.; Lee, Y. Y.; Chang, H.; Jeong, D. H.; Lee, Y.-S.; Kim, M. Y.; Nam, K. T.; Concave Rhombic Dodecahedral Au Nanocatalyst with Multiple High-Index Facets for $\mathrm{CO}_{2}$ Reduction. ACS Nano 2015, 9, 8384-8393.

34. Isab, A. A.; Sadler, P. J. Reactions of Gold(III) Ions with Ribonuclease A and Methionine Derivatives in Aqueous Solution. Biochim. Biophys. Acta 1977, 492, 322-330.

35. A Wu, Z.; Du, Y.; Liu, J.; Yao, Q.; Chen, T.; Cao, Y.; Zhang, H.; Xie, J. Aurophilic Interactions in the Self-Assembly of Gold Nanoclusters into Nanoribbons with Enhanced Luminescence. Angew. Chem. Int. Ed. 2019, 58, 8139-8144.

36. Liao, H.-G; Cui, L.; Whitelam, S.; Zheng, H. Real-time Imaging of $\mathrm{Pt}_{3} \mathrm{Fe}$ Nanorod Growth in Solution. Science 2012, 336, 1011-1014.

37. Cao, X.; Fischer, G. Conformational and Infrared Spectral Studies of L-Methionine and its NDeuterated Isotopomer as Isolated Zwitterions. J. Phys. Chem. A 2002, 106, 41-50.

38. Lone, S. A.; Sadhu, K. K. Gold Nanoflower for Selective Detection of Single Arginine Effect in $\alpha$-Helix Conformational Change over Lysine in $3_{10}$-Helix Peptide. Bioconjugate Chem. 2019, 30, 1781-1787.

39. Laban, B.; Ralević, U.; Petrović, S.; Leskovac, A.; Vasić-Anićijević, D.; Marković, M.; Vasić, V. Green Synthesis and Characterization of Nontoxic L-Methionine Capped Silver and Gold Nanoparticles. J. Inorg. Biochem. 2020, 204, 110958.

40. Wang, W.; Kong, Y.; Jiang, J.; Xie, Q.; Huang, Y.; Li, G.; Wu, D.; Zheng, H.; Gao, M.; Xu, S.; Pan, Y.; Li, W.; Ma, R.; Wu, M. X.; Li, X.; Zuilhof, H.; Cai, X.; Li. R.; Engineering the Protein Corona Structure on Gold Nanoclusters Enables Red-Shifted Emissions in the Second 
Near-Infrared Window for Gastrointestinal Imaging. Angew. Chem. Int. Ed. 2020, 59, 2243122435 .

41. Luo, Z.; Yuan, X.; Yu, Y.; Zhang, Q.; Leong, D. T.; Lee, J. Y.; Xie, J. From AggregationInduced Emission of $\mathrm{Au}(\mathrm{I})$-thiolate Complexes to Ultrabright $\mathrm{Au}(0) @ \mathrm{Au}(\mathrm{I})$-thiolate CoreShell Nanoclusters. J. Am. Chem. Soc. 2012, 134, 16662-16670.

42. Lingaraju, G. M.; Bunker, R. D.; Cavadini, S.; Hess, D.; Hassiepen, U.; Renatus, M.; Fischer, E. S.; Thoma, N. H.; Crystal Structure of the Human COP9 Signalosome. Nature 2014, 512, 161-165.

43. Lavrinienko, A.; Tukalenko, E.; Mousseau, T. A.; Thompson, L. R.; Knight, R.; Mappes, T.; Watts, P. C. Two Hundred and Fifty-Four Metagenome-Assembled Bacterial Genomes from the Bank Vole Gut Microbiota. Sci. Data 2020, 7, 312.

44. Bi, X.; Wang, K.; Yang, L.; Pan, H.; Jiang, H.; Wei, Q.; Fang, M.; Yu, H.; Zhu, C.; Cai, Y.; He, Y.; Gan, X.; Zeng, H.; Yu, D.; Zhu, Y.; Jiang, H.; Qiu, Q.; Yang, H.; Zhang, Y. E.; Wang, W. Tracing the Genetic Footprints of Vertebrate Landing in Non-Teleost Ray-Finned Fishes. Cell 2021, 184, 1377-1391. 


\section{Supplementary Files}

This is a list of supplementary files associated with this preprint. Click to download.

- SI.pdf 